\title{
Sobre el Avant-Propos de Balzac: una perspectiva hermenéutica*
}

\section{A Hermeneutical Perspective on Balzac's Avant-Propos}

Sultana WaHNón

Facultad de Filosofía y Letras

RECIBIDO: 4 DE ENERO DE 2018 Universidad de Granada

Campus de Cartuja s/n. Granada, 18071

swahnon@ugr.es

Orcid ID: 0000-0002-7324-2030

Resumen: Este trabajo versa sobre la poética de la novela contenida en el famoso prólogo de La Comedia humana. En primer lugar, se repasan las tesis centrales de una determinada lectura del texto que, centrándose en los pasajes dedicados a la ciencia moderna, hace de esta el principal modelo de $L a$ Comedia humana. En segundo lugar, se ofrece una relectura del texto desde una perspectiva hermenéutica. La conclusión es que Balzac descartó en este prólogo la posibilidad de servirse de las categorías biológicas para comprender el mundo humano, adelantándose así en cierta medida a la tesis diltheyana sobre la diferencia entre ciencias de la naturaleza y ciencias del espíritu. Finalmente, se destaca el relevante papel desempeñado en el "Avant-Propos" por el modelo literario de Walter Scott, así como en general por la tradición novelesca, cuya defensa y reivindicación habría sido uno de los grandes objetivos de Balzac en este texto teórico.

Palabras clave: Balzac. "Avant-Propos". Ciencia. Historia. Novela.

\begin{abstract}
This paper deals with Balzac's Poetics of the Novel as expressed in his famous prologue to La Comédie humaine. Firstly, I examine a particular reading of the main tenets of this text, which, by focusing on modern science, makes the latter the essential model of La Comédie humaine. Secondly, I offer a new reading from a hermeneutical perspective. Consquently, it may be concluded that Balzac in his prologue refused to understand the human world by means of biological categories, thus becoming a forerunner of Dilthey's differentiation between Natural and Human Sciences (Geisteswissenschaften, 'Sciences of the Spirit'). Lastly, it is necessary to underline what the "Avant-Propos" owes to the literary model of Walter Scott and of the tradition of the novel in general, whose defense and vindication is arguably among Balzac's aims in this theoretical text.
\end{abstract}

Keywords: Balzac. "Avant-Propos". Science. History. Novel.

\footnotetext{
* Este trabajo ha sido realizado en el marco del proyecto de investigación "Actualidad de la hermenéutica" (FFI2013-41662-P), financiado por el Ministerio de Economía y Competitividad para el periodo 2014-2018. Una versión preliminar del trabajo fue presentada en octubre de 2017 en el Congreso Internacional "Humboldt Kolleg: Ficción, conocimiento, interpretación", celebrado en la Universidad de Navarra y financiado por la Fundación Alexander von Humboldt.
} 


\section{INTRODUCCIÓN}

B alzac es un autor que nunca ha dejado de ser estudiado en el ámbito de la filología y de la historia de la literatura, pero al que quizás no se ha prestado demasiada atención por parte de la teoría literaria más reciente. En las últimas décadas la teoría se ha ocupado preferentemente de la narrativa modernista, experimental y/o vanguardista y, por consiguiente, de autores que, como Joyce, Kafka, Woolf, Musil o Camus, suelen caracterizarse justamente por oposición a la estética realista del siglo XIX (ver Barthes 1953; Zima). El desinterés teórico por Balzac y en general por el realismo ha tenido, pues, mucho que ver con el descrédito que habría recaído no solo sobre la idea misma de realismo (ver Villanueva), sino también sobre diversos aspectos de la novela realista que, como la omnisciencia autorial o el monologismo, se habrían ido cargando de connotaciones negativas en el interior mismo del discurso teórico-literario. En el caso de Balzac, todo esto se habría visto agravado por la apropiación marxista de su obra, erigida precisamente en este sistema de pensamiento en el modelo insuperable del realismo (ver Engels; Lukács).

Pese a todo, a lo largo de las últimas décadas no han faltado trabajos que se han ocupado de Balzac desde perspectivas teóricas. El primero y más importante de todos fue sin duda el que el propio Roland Barthes dedicó en 1970 al detenido análisis del relato Sarrasine. Sin embargo, $S / Z$ fue recibido en su día más como una aportación metodológica (crisis del análisis estructural, nueva diseminación del sentido, etc.), que como una relectura o revisión de la obra de Balzac-como también lo es-. En lo que a la revisión o actualización de Balzac se refiere, han tenido por eso más repercusión quizás la serie de aportaciones que en las últimas décadas han contribuido a matizar o relativizar el supuesto realismo de sus novelas. Sería el caso de trabajos que, como los de Elisheva Rosen y Jean-Claude Fizaine (1982) o el más reciente de Rémi Astruc (2010), han subrayado el carácter convencional, artístico e incluso distorsionador (grotesco) de las representaciones balzacianas. En las dos últimas décadas y desde que Rainer Warning publicó Die Phantasie der Realisten (1999), son también muy abundantes los estudios que ponen el énfasis en los aspectos más imaginativos (Brooks) o incluso "fantásticos" de sus relatos (Ledo), lo que explica en parte el interés que en los últimos años despierta el relato filosófico La piel de zapa (Brix; Castelo Branco; Bray; Dickson), al que Pierre Bayard había prestado ya atención en un trabajo pionero de 1978. 
Pero si la imagen del Balzac realista está dejando paso a una nueva percepción del autor como escritor imaginativo, existe otro tópico sobre Balzac que, aunque vinculado al de su realismo, parece resistir mejor al paso del tiempo sin que apenas haya sufrido modificaciones desde que G. Rees lo tematizó en sus diversos trabajos sobre "la influencia" de la ciencia en la novela del siglo XIX (Rees 1955 y 1977; Huertas García-Alejo 31). Desde entonces una parte de la crítica balzaciana ha seguido desarrollando este tema, bien mediante el estudio de los relatos de temática científica de Balzac, tales como Louis Lambert o La Recherche de l'absolu (Ambrière-Fargeaud 1982; Thiher); bien, de manera más frecuente, a partir de las declaraciones teóricas del propio autor, en especial de las contenidas en el famoso Avant-Propos de La Comedia bumana.

Es de este último asunto, el de la teoría contenida en el Avant-Propos, del que va a ocuparse el presente artículo. Para ilustrar sobre su lectura más habitual, se expondrán aquí las opiniones de tres críticos que en principio encarnarían formas diferentes de acercamiento a la literatura. En primer lugar, se atenderá al punto de vista defendido por un representante del tradicional método histórico-filológico, Juan Luis Alborg. Aunque su objeto de estudio era el realismo y el naturalismo en la literatura española, el historiador dedicó a Balzac algunas de las páginas de la "Introducción" al volumen correspondiente de su utilísima Historia de la literatura española (86-94). El interés de estas páginas reside en que dan acogida a la imagen tópica de un Balzac directa y completamente influido por los naturalistas citados en el Avant-Propos: Buffon, Cuvier y Geoffroy Saint-Hilaire. Esta lectura llama tanto más la atención por cuanto que Alborg la defendió justo después de haber reconocido asimismo el "influjo [...] preponderante” de Walter Scott sobre la narrativa balzaciana (87).

A pesar de este reconocimiento expreso, el historiador no dedicó ninguna atención al modelo literario de Scott. Prefirió centrarse en los modelos científicos y, desde ahí, atribuir a Balzac una visión del mundo subsidiaria de la concepción científica de la Naturaleza. Según Alborg, la lectura de los científicos naturalistas le había revelado al escritor "la lucha de los animales para adaptarse al medio", y fue a raíz de esta revelación como pudo concebir "la idea de aplicar a la sociedad humana los principios que aquellos habían deducido de la vida animal", así como llegar a la conclusión de que "había que estudiar las especies sociales como los científicos habían estudiado las especies zoológicas" (87). Esta misma idea fue reiterada por Alborg algo más adelante: a decir suyo, 
tras equiparar "el orden social con el natural", Balzac había pensado que "la sociedad, a semejanza de la Naturaleza, había originado por el influjo del medio, las especies humanas y sociales, equivalentes a las especies zoológicas" (87).

A partir de esta concreta lectura del Avant-Propos, Alborg llegó a la conclusión de que la visión del mundo plasmada en las novelas de Balzac era determinista: "Dentro de esta explicación determinista -escribió el historiador-, las cosas, los objetos, el medio ambiente, adquieren una importancia primordial, puesto que moldean al hombre" (87). Y un poco más abajo, y en coherencia con esta tesis, describió el método balzaciano de creación de personajes en términos que posiblemente habrían convenido mejor a la novela naturalista de Zola: "Todos estos personajes, concebidos por Balzac a la manera de un naturalista, no son seres independientes y razonables, sino simples fuerzas dominadas por las circunstancias" (88).

Junto a esta versión del tópico, la más pura y condensada, existen por supuesto algunas más complejas y sutiles, entre las que no faltan incluso las realizadas desde perspectivas teóricas. Sería el caso por ejemplo del trabajo "La science: modèle ou vérité. Réflexions sur l'Avant-Propos à La comédie bumaine", cuya autora, Françoise Gaillard, especialista en el realismo francés del siglo XIX y también en cuestiones teóricas y epistemológicas, llegó sin embargo a conclusiones muy similares a las de Alborg en relación con el papel de la ciencia en el Avant-Propos. En primer lugar, tampoco en este trabajo se albergaba la menor duda en cuanto a la directa influencia que la ciencia natural había ejercido sobre La Comedia humana. A decir de la autora, el proyecto que Balzac expuso allí era el de hacer en la novela lo que ya se había hecho en la ciencia natural. ${ }^{1}$ En segundo lugar, Gaillard sostuvo asimismo que Balzac había equiparado por completo el orden social con el natural, y que esto le llevó a concebir la idea de aplicar a la sociedad humana los principios que la ciencia había deducido de la naturaleza animal. El escritor había postulado -siguió explicando la autora- un principio de continuidad entre las especies que autorizaba, en alguna medida, "l'extension du savoir sur le règne animal, au plan de l'humain" (65). ${ }^{2}$ A pesar de la diferencia de enfoques, la conclusión de este tra-

1. "Faire, dans l'ordre du roman, ce que Buffon a fait dans celui de la science, tel est bien ce que se propose Balzac" (Gaillard 59).

2. Insistiendo en esta misma idea, la autora añadía que, a partir de la observación de cierta semejanza entre Sociedad y Naturaleza, el escritor se había sentido legitimado para "établir la convenance des méthodes de l'histoire naturelle à l'étude et à la représentation du social" y para "assurer la pertinence des lois naturelles à expliquer les lois de la société, voire de leur légitimité à se confondre avec elles" (65). 
bajo fue, por consiguiente, la misma que se ha visto ya en el de Alborg, a saber, que Balzac había abordado lo humano bajo especie de una realidad natural, "soumise aux seules lois de la nature" (65), es decir, a la manera de un naturalista.

El trabajo de Gaillard contenía, sin embargo, algo más que el de Alborg: una serie de afirmaciones bastante comprometedoras en relación con el único modelo literario que Balzac reconoció en el prólogo. La cuestión del posible influjo de Scott -que Alborg reconoció, aunque luego no lo desarrollara- recibía en cambio bastante atención en el trabajo de Gaillard, si bien para llegar a una conclusión muy poco halagadora para el gran escritor inglés. A la pregunta sobre el papel que Balzac había reservado a Scott en su prólogo (Gaillard 60), la respuesta de la autora fue que se trataba de un papel completamente opuesto al de la ciencia, pues mientras que esta funcionaba como modelo que imitar (70), las novelas de Scott habrían sido citadas por Balzac a manera de contra-modelo (61). Según la estudiosa, el escritor había hecho comparecer a Scott única y exclusivamente para señalar la laguna, le défaut, de sus novelas (60). Gaillard aludía con esto al pasaje del Avant-Propos en el que Balzac señaló, en efecto, lo que faltaba en la genial obra de Scott: la ligazón de las novelas, la coordinación de una historia completa en la que cada capítulo fuese una novela (Balzac 10). Pero, extrayendo esta afirmación de su contexto verbal, Gaillard llegó a la sorprendente conclusión de que el único escritor al que Balzac dedicó una página del prólogo estaba allí a manera de referencia esencialmente negativa (Gaillard 61).

Para terminar con esta sucinta revisión del tópico de un Balzac "fascinado por la ciencia" (ver Ambrière-Fargeaud 1982, 43), me referiré a una contribución más reciente, la de Allen Thiher en su libro Fiction Rivals Science (2001), cuyo primer capítulo se dedica al novelista francés con el título de "Balzac and the Unity of Knowledge" (Thiher 37-80). La tesis central del libro de Thiher, en el que se inserta este capítulo sobre Balzac, es precisamente un desmentido de la tesis acerca de la "influencia" que la ciencia habría ejercido sobre la novela del XIX en general y sobre la de Balzac en particular. Para este autor, la relación entre novela y ciencia a lo largo del siglo XIX debería describirse, mejor, en términos de rivalidad y competencia. Esta perspectiva según la cual los discursos de la ciencia y la novela entraron en el siglo XIX en una rivalidad epistémica (39), la complementa Thiher con otra según la cual la novela no habría rivalizado únicamente con la ciencia, sino con otros discursos prestigiosos del siglo XIX tales como la metafísica o la historia. La historia 
de la novela del siglo XIX tendría que ser por eso, concluía Thiher a este respecto, una historia de su reacción a -e interacción con- discursos epistémicos tan diversos como la metafísica, la historia y la ciencia natural. ${ }^{3}$

Tan atinado planteamiento no desemboca, sin embargo, en una revisión radical del tópico de un Balzac predominantemente científico, debido a la decisión de Thiher de centrarse exclusivamente en el asunto de la rivalidad con la ciencia, o como también lo formula, en el encuentro de la novela con la ciencia natural (39), excluyendo pues de su campo de interés las interacciones de la narrativa del siglo XIX con cualquiera otro de esos diferentes discursos epistémicos. El capítulo sobre Balzac sería, pues, una nueva aportación al tema de su apasionada relación con las ciencias naturales. ${ }^{4}$ Se trata, eso sí, de una aportación mucho más elaborada y sutil que las antes analizadas, puesto que entre otras cosas presta una inusual atención a los que el autor llama los "relatos epistémicos" de Balzac (48), los ya mencionados Louis Lambert, La Recherche de l'absolu, etc. Para lo que aquí nos interesa, lo más importante sería con todo su cuestionamiento del uso del término "influencia" también para el caso de Balzac: tras calificar de engañosa la idea de que el escritor fue influido por los científicos de su tiempo, ${ }^{5}$ Thiher ha propuesto hablar más bien de una convergencia con ellos en lo que respecta a sus intereses teóricos. ${ }^{6}$

Pese a la profunda diferencia entre este planteamiento y el de los estudiosos antes citados, el trabajo de Thiher acaba llegando a conclusiones, no idénticas, pero sí muy similares a las que ya conocemos. El motivo de esto es su concreto entendimiento de cuáles fueron los intereses teóricos en los que convergieron ciencia y novela del XIX. Para Thiher, la convergencia entre Balzac y la ciencia se habría basado en una misma creencia o interés, el de "the Unity of Knowledge". Desde esta perspectiva, que de hecho da título a su capítulo sobre Balzac, Thiher no niega que el novelista aspirase a una explicación unitaria de mundo social y mundo natural; lo que cuestiona es que esto ocurriese así por influencia o emulación de la ciencia: Balzac no habría tenido

3. "The history of the novel, beginning with Balzac and, with some restrictions, Stendhal, is a tale of its reaction to, and interaction with, epistemic discourses as various as metaphysics, history, and natural science" (Thiher 39).

4. El propio Thiher $(69, \mathrm{n} .15)$ cita a algunos de sus predecesores en el tratamiento de este asunto, entre ellos la aquí también citada Madeleine Ambrière-Fargeaud.

5. "It is perhaps a bit misleading to maintain that Balzac was influenced by the biology that was being formulated in Paris by Lamark, Geoffroy Saint-Hilaire, and Cuvier" (Thiher 46).

6. "It is more accurate to speak of a convergence of theoretical interests in which Balzac found, in contemporary biology, analogies with his own epistemic vision" (Thiher 47). 
necesidad alguna de los científicos naturalistas de su tiempo para llegar a concebir esta posibilidad, puesto que previamente a sus lecturas científicas él mismo había abrigado ya la aspiración ilustrada a representar "the totality of Knowledge" (39). Por idénticas razones, tampoco habría necesitado del concurso de la ciencia para concebir muchas de sus ideas más características, entre las que Thiher menciona expresamente la de estudiar el mundo social mediante homologías con el mundo natural.?

La originalidad del trabajo de Thiher reside, entonces, en presentarnos a un Balzac más creador que imitador, esto es, a un escritor que en lugar de dejarse influir pasivamente por la visión científica del mundo, estaba más bien defendiendo su propia y totalizadora teoría, en la que sociedad y naturaleza se fundían en una unidad. ${ }^{8}$ Por lo mismo, y aunque el trabajo de Thiher es, ya se ha dicho, mucho más sutil que los anteriores, su lectura no acaba de disipar del todo la imagen de un Balzac científico, o si se quiere racional-ilustrado, pero que en cualquier caso habría creído firmemente en la posibilidad de estudiar conjuntamente sociedad y naturaleza. Esto explica que Thiher haya podido concluir que el novelista se sirvió de la biología y la tradición taxonómica de la ciencia natural como categorías para comprender el mundo humano (46); o incluso presentarlo, de manera muy similar a Gaillard, en abierto enfrentamiento con la tradición literaria, cuyos clásicos "tipos" o "caracteres" habría convertido Balzac, según este estudioso, en una taxonomía al estilo de Buffon.?

\section{El AVANT-PROPOS A LA LUZ DE LA HERMENÉUTICA}

A diferencia de las lecturas que acaban de resumirse, la que va a proponerse aquí se realiza desde una perspectiva hermenéutica. La distancia crítica que la filosofía del comprender mantiene respecto del modelo positivista del conocimiento permitirá dar cuenta aquí de algunos aspectos de la reflexión contenida en el Avant-Propos a los que no se ha prestado demasiada atención. La finalidad del trabajo es poner de manifiesto la raigambre, más humanista y

7. "Balzac theorized that, since human nature is encompassed by the presupposed totalization of knowledge, the nature of human society can be explained through its homologies with the entire natural words" (Thiher 46).

8. "Balzac admired both scientists for underwriting different aspects of his own totalizing theory in which society and nature are fused as a unity" (Thiher 47; cursiva nuestra).

9. "In his novels, Balzac wants to describe not just isolated classical «types» or caracteres of the moraliste tradition, but related taxa that can be defined in terms of a totality of interrelationships" (Thiher 46). 
hermenéutica que científica, del pensamiento literario de Balzac. No obstante, esta relectura hermenéutica adoptará como punto de partida una de las tesis de Thiher que acaban de exponerse: la novela de Balzac fue, en efecto, una reacción a (y una interacción con) una serie de diferentes discursos epistémicos, entre ellos la Ciencia y la Historia. No se coincidirá, en cambio, con este mismo estudioso en lo que concierne a la presunta convergencia entre los intereses de la Ciencia y los de Balzac. Se cuestionará asimismo que Balzac se sirviera de las categorías biológicas para comprender el mundo humano, despreciando en cambio las viejas categorías de la tradición literaria. Se destacará, por el contrario, el relevante papel desempeñado en el Avant-Propos por el modelo literario de Walter Scott, así como en general por la tradición novelesca, cuya defensa y reivindicación habría sido la gran finalidad de Balzac en este texto teórico.

\section{El imposible modelo de la Ciencia}

Lo primero que cabe señalar en este sentido es que la Ciencia no es el primer discurso que el autor citó en el Avant-Propos. La referencia a Cuvier y SaintHilaire se encuentra ciertamente muy pronto: en el tercer párrafo del prólogo. Es, por tanto, comprensible que esta insólita comparecencia de la ciencia natural en un prólogo literario haya despertado el interés y la atención de tantos estudiosos. Sin embargo, el párrafo que contiene esa importante referencia a los naturalistas de su tiempo va precedida de otros tres a los que se ha prestado mucha menos atención, a pesar de que es en el primero de esos párrafos, el que abre el texto, donde se encuentra la primera referencia culta del prólogo, que no lo es a científicos, sino a escritores: "Corneille, Molière y otros grandes autores" (Balzac 7). ${ }^{10}$ Importa destacar además que es solo a estos grandes escritores, y no a los científicos, a los que Balzac dice expresamente querer emular (leur ressembler). Los grandes poetas dramáticos son, pues, el primer y confesado modelo del Avant-Propos, aun cuando no se trate todavía, como luego ocurrirá con Walter Scott, de un modelo literario, sino crítico: al haberse decidido a escribir un prólogo a modo de poética, Balzac quiso hacer suya la "modestia" y falta de "vanidad" con las que en su día esos

10. El Avant-Propos se cita aquí por la edición de Gallimard que se referencia en el apartado bibliográfico, al final de este trabajo. Las traducciones que se ofrecen de los textos son nuestras, aunque se han confrontado con ediciones españolas del texto. 
grandes autores habían examinado (en el doble sentido de analizar y evaluar) su propia obra. Tomándolos como ejemplo, Balzac se presentó a sí mismo decidido a examinar la idea (la pensée), el origen (l'origine) y el plan (le plan) de su obra con la misma ecuanimidad con que esos grandes pero modestos autores lo habrían hecho: "como si no estuviese interesado en ello" (7).

Como es lógico, Balzac escribió el prólogo para defender su proyecto narrativo. Sin embargo, no puede descartarse que, en conformidad con sus expresas intenciones, optara por abordar el asunto de manera relativamente distanciada y con algo de desinteresada autocrítica. En mi opinión, el primer indicio de esta ecuánime actitud se encuentra en su decisión de "contar el origen" (raconter l'origine) del proyecto. Al hacerlo así y utilizar consecuentemente la forma verbal del pasado (fut, vint, vis...), el escritor pudo situarse a cierta distancia (histórica) de la que él mismo llamó "l'idée première" de su obra. Y en esto consiste precisamente la hipótesis que se va a defender en el presente trabajo, a saber, que Balzac no escribió el Avant-Propos para defender su plan tal y como lo había concebido en sus orígenes, sino para narrar la evolución que había ido experimentando a lo largo del tiempo. Esto explica que el autor optase, ya en el segundo párrafo del prólogo, por hablar de esa idea primera en términos de "sueño", "proyecto imposible" y fantástica "quimera":

La primera idea de La comedia bumana surgió en mí, primero, como un sueño, como uno de esos proyectos imposibles que se acarician y se dejan escapar; una quimera que sonríe, que muestra su rostro de mujer y que despliega enseguida sus alas remontándose a un cielo fantástico. (7)

¿Fue de verdad el Balzac joven quien concibió su proyecto "como un sueño”? ¿O era más bien el Balzac maduro, el que estaba escribiendo el prólogo, quien desde su nueva y más amplia perspectiva lo juzgaba un sueño y una quimera? El presente trabajo se inclina por esta segunda posibilidad, que parece encontrar confirmación en la inmediata alusión de Balzac a la "tiranía" que esa primera y quimérica idea, convertida ya en "realidad", ejercía ahora sobre él: "Pero la quimera, como muchas otras quimeras, se trueca en realidad, tiene sus mandamientos y su tiranía a los que hay que ceder" (7).

El tercer párrafo lo compone una única y muy breve oración: "Esta idea surgió (vint) -escribió- de una comparación entre la Humanidad y la Animalidad" (7). Como se ve, el autor no informaba todavía acerca de cuál había sido esa quimérica idea primera, sino solo acerca de cómo se le ocurrió. La comparación entre Humanidad y Animalidad no era, pues, la quimérica idea a la que 
acababa de referirse. Entre otras cosas porque no era de su autoría. Nada más mencionarla, Balzac se sintió por eso obligado a rendir homenaje a su verdadera responsable, la Ciencia. En lo que a esta idea respecta, el escritor no sintió por tanto la necesidad de retractarse: la posibilidad de comparar Humanidad y Animalidad era algo en lo que seguía creyendo firmemente. $Y$ esto tanto en su versión más actual, la del debate entre Cuvier y Saint-Hilaire, como en la variante ilustrada que el escritor se esforzó en reivindicar en el prólogo. A pesar de lo defendido por Thiher, no se detecta, pues, el menor indicio de rivalidad o competición con la Ciencia. Sin embargo, esto no quiere decir que la relación de Balzac con el discurso científico de su época fuese, como por su parte quería Madeleine Ambrière, de ciega fascinación. Prueba de ello es la advertencia con la que el escritor dio comienzo precisamente al cuarto y decisivo párrafo del prólogo, avisando a los lectores del "error" que suponía creer que el "gran debate" de los últimos tiempos (dans ces derniers temps) reposaba sobre "una innovación científica" (7).

$\mathrm{Al}$ sostener que no todo era nuevo en el debate entre Cuvier y SaintHilaire, Balzac no estaba tratando de restarle valor a "la alta ciencia" de su tiempo, pero sí de reivindicar el olvidado mérito de "los más grandes espíritus de los dos siglos anteriores", que fue como se refirió a una serie de figuras, fronterizas entre la Ciencia y la Filosofía -Leibniz, Buffon, Bonnet, Swedenborg, Saint-Martin-, todos ellos ajenos desde luego a la nueva época de la especialización que se encarnaba en las figuras de Cuvier y Saint-Hilaire, pero no por ello menos "científicos" a ojos de Balzac (7-8). Aunque con otros términos (sous d'autres termes), todos estos pensadores ilustrados se habían anticipado a la tesis a la que Saint-Hilaire había dado el reciente nombre de "unité de composition" (7) y que hoy se traduciría por unidad de la materia. La idea de que todas las sustancias posibles eran modificaciones de una misma materia fue suscrita por Balzac desde muy pronto (ver Ambrière-Fargeaud 1976, 1118), y por lo mismo, en lo que a ella se refería, el escritor se limitó a reconocer la deuda contraída con la Ciencia, en especial con los pensadores ilustrados, de cuyo "sistema" se declaró por eso "penetrado" antes incluso de los debates científicos a los que había dado lugar en fechas recientes (8).

Cosa diferente ocurría -y Balzac no vaciló tampoco en reconocerlo- con la tesis de que las diferencias entre las especies procedían de "los medios en los que él (el animal) estaba forzado a desarrollarse" (8). En ella encontraba Balzac la verdadera innovación y, por tanto, el gran mérito de Saint-Hilaire, cuyo "triunfo" en el debate saludó por eso como ya lo había hecho "el gran Goe- 
the" (la segunda cita literaria del prólogo). ${ }^{11}$ El novelista no dudó, pues, en reconocerle a Saint-Hilaire el "eterno honor" de que esta tesis le había hecho merecedor, confirmando así la impresión de que, sin sentimiento alguno de rivalidad, era consciente del alto lugar que las ciencias de la naturaleza estaban llamadas a ocupar en el sistema de conocimiento de las sociedades modernas. Más allá de sus posiciones conservadoras en lo político y en lo moral, el autor se mostró desde el comienzo mismo del prólogo -y como para que nadie pudiera albergar dudas al respecto- persuadido por las revolucionarias tesis de la biología moderna, tanto en lo que se refería a la unidad de origen de las especies vivas ("No hay más que un animal"), como en lo que concernía a la influencia que el medio (milieu) había tenido en su desarrollo y en sus posteriores diferencias formales: "El animal es un principio que toma su forma exterior, o, para hablar con más exactitud, las diferencias de su forma, en los medios donde está llamado a desarrollarse" (8).

Balzac no negó, pues, la influencia que las ciencias naturales habían tenido en su pensamiento sobre la Naturaleza -incluyendo dentro de este concepto a la especie humana-. Pero esto no significa, como quería Gaillard, que el autor defendiera una extensión del saber sobre el reino animal al plano de lo humano-social. Ciertamente, en esto había consistido la que Balzac llamó su "primera idea", sobre la que informó por fin nada más arrancar el quinto párrafo: "Penetrado de este sistema mucho antes de los debates a los que ha dado lugar, vi que, en este aspecto, la Sociedad se parecía a la Naturaleza" (8; cursivas nuestras). Expresada otra vez en pasado, esta parte del relato daba cuenta ya de cuál había sido esa primera y quimérica idea que estuvo en el origen de su proyecto y que consistió, no en la atinada comparación entre Humanidad y Animalidad, sino en otra, mucho más arriesgada y de la entera responsabilidad de Balzac, entre Sociedad y Naturaleza.

La forma verbal en pasado no es, por otro lado, el único indicio de la distancia con la que Balzac expuso en el prólogo su primera hipótesis. Más reveladora aún resulta la manera en la que el escritor decidió formular acto seguido la idea, derivada de esta primera, de una posible homología entre las especies animales y lo que él había decidido llamar "especies sociales". En lugar de hacerlo de manera aseverativa, como habría convenido a una tesis fir-

11. Balzac se refirió aquí al "último artículo" del "gran Goethe", en el que ese triunfo de SaintHilaire ya había sido reconocido y saludado. Se trataba del artículo titulado "Les Naturalistes français”, publicado en marzo de 1832 (véase Ambrière-Fargeaud 1976, 1118). 
me y sólida, el escritor lo hizo entre interrogaciones, a manera pues de hipótesis: "La Sociedad -se preguntó- ¿no hace del hombre, según los medios en los que su acción se despliega, tantos hombres diferentes como variedades hay en zoología?" (8).

La lectura más habitual del prólogo, la examinada en la primera parte de este trabajo, reposa en la convicción de que la respuesta del Avant-Propos a esta interrogante habría sido completamente afirmativa: el escritor habría equiparado aquí Sociedad y Naturaleza sosteniendo por ende que ambas podrían estudiarse de la misma manera, esto es, distinguiendo variedades (especies) sociales en función del "medio", exactamente igual que los naturalistas habían hecho con las variedades animales. Se trata de una lectura que, además, parece encontrar apoyo en las dos afirmaciones que en el prólogo siguen a la pregunta. En primer lugar, la del paralelismo entre las diferencias que separaban a las especies animales y las que resultaban del ejercicio humano de una determinada profesión: "Las diferencias entre un soldado, un obrero, un administrador, un abogado [...] son -escribió Balzac-, aunque más difíciles de percibir, tan considerables como las que distinguen al lobo, al león, al asno..." (8). $\mathrm{Y}$ en segundo lugar, la consecuente posibilidad de hablar de esas mismas profesiones en términos de "especies sociales": "Existen, pues, y existirán en todos los tiempos Especies Sociales igual que existen Especies Zoológicas" (8).

El objetivo de las páginas que siguen es, sin embargo, arrojar una duda sobre esta lectura a partir de los indicios textuales que también permiten sostener lo contrario, es decir, que la respuesta del Avant-Propos a la interrogante no habría sido afirmativa. Con esto no se pretende decir que Balzac no hubiera creído nunca en la pertinencia -siquiera fuese metafórica- de la equivalencia, que de hecho se encuentra en otros textos anteriores del autor (ver Ambrière-Fargeaud 1976, 1112). Se trata solo de plantear que quizás esto ya no era del todo así en el momento de plena madurez en que escribió el AvantPropos (1842). Ciertamente, y como acaba de verse, el autor reiteró sus viejas hipótesis al respecto. Sin embargo, es muy posible que lo hiciese solo a modo de recordatorio de las que habían sido sus primeras ideas al respecto. Conviene reparar a este respecto en que la afirmación según la cual existían especies sociales "igual que existen Especies Zoológicas" no era el final del prólogo. Nada más exponerla, el autor puso ya sobre la mesa la que debía ser la lógica consecuencia de lo antedicho: si las diferencias entre los seres humanos se explicaban por el medio social y si, por consiguiente, se podía afirmar la existencia de especies sociales equiparables a las animales, entonces lo razonable 
era pensar que la Sociedad podía ser estudiada igual que se estudiaba la Naturaleza. Sin embargo, esta lógica conclusión no fue expuesta a manera de tesis, sino otra vez de hipótesis, es decir, entre interrogaciones: "Si Buffon -se preguntó Balzac- ha hecho una obra magnífica tratando de representar en un libro el conjunto de la zoología, ¿no estaba por hacer una obra de esta clase para la Sociedad?".

De haber contestado a esta pregunta en sentido afirmativo, se podría sostener, como lo hizo Madeleine Ambrière, que Balzac fue un autor fascinado por la Ciencia y que La Comedia bumana sería una obra "scientifique" (Ambrière-Fargeaud 1982, 54). También estaríamos legitimados para convenir con ella, y con Thiher, en que el autor habría compartido con la Ciencia la aspiración a la unidad del conocimiento, puesto que una respuesta afirmativa a esta pregunta significaría que el autor creyó siempre y firmemente en la posibilidad de escribir una obra que fuese, para la Sociedad, lo que el tratado de Buffon había sido para la Naturaleza. La quimera de Balzac se nos aparecería entonces como la gran quimera del positivismo: la de estudiar lo humano-social con los mismos métodos y fines de las ciencias naturales.

La hipótesis que este trabajo defiende es, sin embargo, que Balzac acertó por sí mismo a percibir el carácter quimérico e imposible de esta idea. El primer argumento a favor de esta hipótesis se encuentra en la respuesta negativa que el propio autor dio acto seguido a esta segunda interrogante. Me refiero a la oración adversativa en la que el autor advirtió clara y expresamente sobre la imposibilidad de mantener el estudio de la Sociedad en los "límites" en los que necesariamente debía mantenerse el estudio de la Naturaleza: "Pero la Naturaleza ha impuesto, a las variedades animales, límites entre los cuales la Sociedad no podía mantenerse" (8; cursiva nuestra). A esta oración seguía luego, en el mismo párrafo quinto, un largo discurso, este ya completamente aseverativo -sin ninguna interrogante-, en el que Balzac fue exponiendo una por una las diferencias que había ido encontrando entre especies animales y "especies" sociales.

Un breve excurso se hace necesario en este punto. Lo que motivó a Balzac a proponer una equivalencia entre las especies naturales y las supuestas "especies sociales" había sido su convicción de que, más allá de la proclamación revolucionaria de la égalité entre los seres humanos, existían y existirían siempre diferencias entre ellos. Pero en un primer momento (y en eso había consistido su error) el autor pudo quizás creerlas atribuibles únicamente al "medio" social en el que los seres humanos, pareciéndose sous ce rapport a los 
animales, se veían obligados a desarrollarse. En cambio, en el momento en que escribió el prólogo, esa "primera idea" había sido descartada o, por lo menos, relegada al nivel de equivalencia metafórica. Tal como ahora lo veía Balzac, existían, por supuesto, diferencias entre los seres humanos, pero estas no podían ser explicadas solo por la influencia del medio: Naturaleza y Sociedad no eran idénticas, ni siquiera sous ce (modesto) rapport. De ahí que el discurso insertado en este momento del prólogo no fuese, como habría cabido esperar, una argumentación a favor de la supuesta analogía entre especies sociales y animales, sino en contra de la misma. Lo que el autor ofreció aquí fue la larga serie de razones por las que resultaba imposible aplicar a la sociedad, de manera mecánica, el concepto naturalista de "especies".

El primero de esos argumentos fue el de la imposibilidad de comprender las diferencias entre hombre y mujer a la luz del concepto de especie social. Balzac explicó aquí que, a diferencia de lo que ocurría en el mundo animal, donde la leona era simplemente la hembra (femelle) del león, la mujer y el hombre de una misma especie social podían ser en cambio "dos seres perfectamente disímiles" (8-9). Se trata de un pasaje del prólogo muy comentado, pero del que creo no se ha destacado lo más importante: al sostener que la mujer de un mercader era "digna" a veces de ser la mujer de un príncipe, Balzac estaba arrojando un desmentido sobre su "primera idea", esa según la cual las diferencias entre los humanos se explicaban, como las animales, solo por la influencia del medio. Por lo mismo, estaba cuestionando velis nolis ese primer proyecto de hacer una obra como la de Buffon. Esto es al menos lo que se infiere de la afirmación según la cual, con solo que se tuvieran en cuenta las diferencias entre los sexos, la "descripción" de las (supuestas) "Especies Sociales" tendría que haber sido "al menos doble que la de las Especies Animales" (9; cursiva nuestra).

Que esto significaba la renuncia de facto al concepto de "Especies Sociales", así como a la posibilidad de estudiarlas a la manera de un naturalista, se ve confirmado por el hecho de que esta sea la última vez en que dicho concepto hace acto de presencia en el prólogo, donde ya no vuelve a aparecer -en ninguna de sus diez siguientes páginas-, ni siquiera a modo de metáfora. $\mathrm{Na}-$ turaleza y Sociedad no eran, pues, lo mismo, ni podían ser estudiadas de la misma manera. $\mathrm{Y}$ en esto habría consistido la verdadera conclusión a la que el escritor llegó en el prólogo y que expuso nada más terminar su reflexión sobre la diferencia de género: "El Estado Social tiene contingencias (hasards) que la Naturaleza no se permite, pues él es la Naturaleza más la Sociedad” (9). 
Este breve aserto permite inferir que, si Balzac fue alguna vez víctima de un espejismo cientificista, esto había dejado de ser así en el momento en que escribió el Avant-Propos. De ahí que me atreva a ver en esta reflexión balzaciana un precedente de la hermenéutica filosófica, esto es, de la hermenéutica entendida como teoría no positivista del conocimiento. La relación entre Balzac y la hermenéutica ha sido ya objeto de algunos trabajos que han proseguido la línea iniciada por el $S / Z$ de Barthes, indagando por tanto en la configuración hermenéutica de sus relatos y novelas (ver Lyon-Caen 2003 y 2012; Del Lungo; Del Lungo/Lyon-Caen). Lo que aquí se propone es, en cambio, ver en Balzac a un temprano precedente de la teoría hermenéutica del conocimiento: al establecer una clara línea divisoria entre el mundo animal (natural) y el mundo humano (natural-social), el novelista se habría adelantado a la tesis filosófica, epistemológica, de una necesaria diferenciación entre ciencias de la naturaleza y ciencias del espíritu -e incluso, acercándose ya a Habermas, también entre ellas y las ciencias sociales-. Es así como puede en efecto leerse el resto del párrafo, donde se proporcionan diferentes argumentos a favor de la necesidad de diferenciar entre los dos objetos de estudio: animales y humanos luchaban entre sí, pero no por las mismas razones; ${ }^{12}$ los animales habían posiblemente evolucionado, pero no lo hacían al mismo ritmo en que podía hacerlo un ser humano a lo largo de su corta vida $;{ }^{13}$ los animales se limitaban a vivir, en tanto que los humanos además representaban la vida; ${ }^{14} \mathrm{y}$ por último y más importante, mientras que los hábitos de los animales eran relativamente estables, las costumbres humanas, a más de ser diferentes en función del grupo social (artistas, banqueros, etc.), cambiaban a la par de las civilizaciones. ${ }^{15}$

Aun cuando Balzac no lo hiciera explícito, toda esta argumentación sobre las diferencias entre animales y seres humanos (o sociales) conllevaba una

12. "En fin, entre los animales hay pocos dramas, la confusión no se suscita apenas entre ellos; se lanzan los unos contra los otros, eso es todo. Los hombres también se lanzan los unos contra los otros; pero su mayor o menor grado de inteligencia hace que el combate se complique de otro modo" (9).

13. "Si algunos sabios no admiten todavía que la Animalidad se transfunda en la Humanidad por medio de una inmensa corriente de vida, el tendero llega ciertamente a par de Francia, y el noble desciende a veces al último rango social" (9).

14. "El animal tiene poco mobiliario, no tiene ni artes ni ciencias; mientras que el hombre, por una ley que todavía no se ha investigado, tiende a representar sus costumbres, su pensamiento y su vida en todo lo que adapta a sus necesidades" (9).

15. "Los hábitos de cada animal son, al menos a nuestros ojos, constantemente idénticos en todo tiempo; mientras que los hábitos, las ropas, las palabras, las viviendas de un príncipe, de un banquero, de un artista, de un burgués, de un sacerdote y de un pobre son enteramente diferentes y cambian a la par de las civilizaciones" (9). 
implícita renuncia al viejo concepto de "especies sociales", que desde esta nueva perspectiva se quedaba sin más validez, si acaso, que la de una metáfora poco afortunada. A despecho de lo que él mismo pudo haber pensado en otro momento, la enorme complejidad de la vida social hacía imposible toda equiparación entre especies naturales y especies sociales, convirtiendo así en ilusorio y quimérico el plan originario de La Comedia bumana. Esto explica que, nada más finalizar este largo discurso, Balzac ofreciera, ya en el sexto párrafo del prólogo, lo que propongo entender como una redescripción del plan de su obra, de la que excluyó por completo la noción de "especies sociales", sustituida aquí por las mucho más tradicionales y humanistas de "hombres", "mujeres", "personas", "representación”, "pensamiento" y "vida": "Así -escribió Balzac- la obra por hacer debia tener una triple forma: los hombres, las mujeres y las cosas, es decir, las personas y la representación material que ellas se dan de su pensamiento; en suma, el hombre y la vida" (9; cursivas nuestras).

\section{La relación con la Historia}

No puede, pues, sorprender que, una vez expuesto este nuevo y más acertado plan de trabajo, Balzac se olvidase por completo de las ciencias naturales para acordarse en cambio de la Historia, la segunda de las disciplinas o epistemes a las que prestó atención en el prólogo -o con las que, por decirlo en términos de Thiher, habría interactuado-. Esta repentina invocación a la Historia en el séptimo párrafo del texto sugiere que, una vez descartado el plan originario de escribir novela bajo la advocación de Buffon -y, por tanto, de la Ciencia-, era la Historia, una disciplina genuinamente hermenéutica, la que a juicio de Balzac debía comparecer en tanto que discurso capaz de dar cuenta de la especificidad del mundo humano. Al fin y al cabo, la Historia era la disciplina que desde siempre se había venido ocupando de las contingencias de la vida social. Es comprensible, pues, que Balzac prefiriera a partir de cierto momento representarse a sí mismo, no a imagen de los "pacientes zoógrafos" que describían la "excesivamente sencilla" vida de los animales (9), sino a imagen del historiador que podía dar cuenta de la gran complejidad de la vida humana.

La preferencia por la Historia como modelo epistémico de su plan narrativo quedaría probada por el primer título que Balzac le puso, que no fue otro que el de Histoire de France pittoresque (ver Ambrière-Fargeaud 1976, 1110). Incluso en el hipotético caso de que no hubiera llegado a darle el definitivo y más literario título de La Comedia bumana, esto sería suficiente para arrojar un de- 
finitivo desmentido sobre la idea de que Balzac hubiera concebido su obra a la manera de un tratado científico. De haber querido emular algún saber, este habría sido el histórico, no el científico. Ahora bien, ni siquiera esto sería correcto del todo, al menos en lo que al Avant-Propos se refiere. La relación que Balzac estableció aquí entre Novela e Historia no fue de completa identidad, sino de semejanza-diferencia. Y el modelo no confesado que informó su reflexión sobre esa relación fue sin duda la poética clásica, donde el parentesco entre Historia y Poesía se basaba tanto en una semejanza (ambas se ocupaban de las acciones humanas), como en una diferencia: una contaba lo que había sucedido, y otra lo que podía suceder, lo verosímil (Poética 1451b). Ahora bien, en la Poética esto se había dicho únicamente en relación con los géneros épicos y dramáticos. La novela, fruto tardío del arte verbal del que Aristóteles nada supo y del que la poética humanista nada quiso saber, había vivido por eso durante siglos completamente al margen del sistema de la Poética, o por decirlo en palabras recientes de Thomas Pavel, "desprovisto del título de nobleza del que se enorgullecían la epopeya y la tragedia” (Pavel 15).

Al defender su relación con la Historia, Balzac, al igual que otros escritores y pensadores del momento, estaba tratando de rellenar esta laguna de la Poética incorporando el género novelesco tanto al viejo sistema aristotélico como al moderno sistema de las Bellas Artes. Tal como él lo veía, la marginación del género se había debido, entre otras cosas, a su secular desinterés por ese importante requisito del arte poético que era la verosimilitud. Este fue sin duda el sentido de la objeción que, con toda delicadeza y amabilidad, hizo Balzac a una opinión pasada de Mme. Necker, la madre de Mme. De Staël:

La historia es o debería ser lo que fue; mientras que la novela debe ser el mundo mejor, ha escrito Mme. Necker, uno de los espíritus más distinguidos del último siglo. Pero la novela no sería nada si, dentro de esta augusta mentira, no fuese verdadera en los detalles. (15)

Lo que Balzac compartía con este aserto de su ilustre predecesora era, por supuesto, la idea aristotélica de que la Historia era y debía ser "lo que fue"; en lo que respecta a la Novela, en cambio, Balzac seguramente no habría dicho que debía ser "el mundo mejor", sino si acaso "el mundo diferente". Pero, en lugar de discutir sobre esto (pues no tenía inconveniente en aceptar que su novela seguía teniendo algo de representación idealizada del mundo real), prefirió limitarse a señalar que, aun dentro de esa "augusta mentira" en que toda novela debía consistir, era necesario -si se quería que la novela llegara a 
ser algo en lugar de "nada"- "ser verdadero en los detalles", o dicho de otro modo, que la novela se incorporara al reino de la verosimilitud. Se ve, pues, que el escritor estuvo muy lejos de proponer una identidad entre Novela e Historia. De lo que se trataba era, más bien, de que la novela, sin dejar de ser esa augusta mentira a la que damos hoy el nombre de ficción, renunciara a los excesos de la imaginación romanesque, transformándose en una nueva modalidad de representación verosímil de la vida y aproximándose así a la definición aristotélica de la Poesía. Desde la perspectiva de Balzac, este acercamiento no debía suponer disolución del género novelesco en el género histórico, ni tampoco una completa renuncia a la imaginación creadora, ya que de ser así no habría podido escribir ese famoso aserto del prólogo en el que se declaró "más libre" que el historiador: "He hecho más que el historiador, porque soy más libre" (15).

Pero, además de por la oposición entre lo verdadero y lo verosímil, Historia y Novela se diferenciaban en otro aspecto hasta entonces inadvertido y del que ni siquiera Aristóteles había dicho nada. Se trataba de la diferencia entre la Historia y lo que Unamuno iba a llamar algo más tarde la "intrahistoria". Balzac reparó, en efecto, en que los hechos "reales" de los que se ocupaba la Historia eran siempre e invariablemente los grandes "acontecimientos de la vida pública de las naciones" (Balzac 17). Los historiadores no solían ocuparse, en cambio, de los pequeños hechos y "dramas" de la "vida privada" (9), como tampoco de informar acerca de las cambiantes y poco duraderas costumbres humanas. El autor atribuyó esta "inmensa laguna en el campo de la historia" a un "olvido" por parte de quienes se habían dado por cometido la escritura de la Historia: "Los escritores se han olvidado, en todos los tiempos, en Egipto, en Grecia, en Persia, en Roma, de darnos la historia de las costumbres" (9; cursiva nuestra). Pero, en realidad, más que de un olvido, se trataba -como acababa revelando la propia argumentación de Balzac- de una limitación genérica: no era competencia de la Historia dar cuenta de esa "historia olvidada" (11). Por lo mismo, no era la Historia sino la Novela la que podía y debía rellenar esa inmensa laguna del conocimiento, algo que sin embargo solo podría hacer si, tal como había planteado a propósito del aserto de Mme. Necker, restringía su libertad creadora para dar entrada a un cierto grado de "verdad" en la representación de la existencia humana.

Así reformulado y entendido, el "plan" narrativo de Balzac era un plan literario, novelesco y ficcional; no un plan histórico. Pero era un plan novelesco que se entendía en cierta relación con la Historia, que pretendía comple- 
mentar a (o incluso rivalizar con) el saber histórico. Nada, como se ha visto, que no pueda ser explicado a la luz de la poética clásica, pero sobre todo nada que autorice a hablar de su obra como puesta en práctica de un proyecto de carácter científico o naturalista. Y lo mismo ocurriría, como enseguida va a verse, con el papel desempeñado en el prólogo por el modelo literario de Walter Scott.

\section{Los modelos literarios}

A diferencia de lo que sostenía Françoise Gaillard, la novela de Walter Scott no habría sido el "contra-modelo" de Balzac, sino su verdadero y único modelo en el sentido estricto de la palabra. Tras haber dado cuenta de las diferencias entre Historia y Novela -dos géneros discursivos que podían solaparse, pero no confundirse-, el escritor se centró ya en la descripción y caracterización del género novelesco, dentro del cual inscribió su propia obra y con el que no temió que se le confundiera. Muy al contrario, toda esta parte del prólogo, que coincide con el octavo párrafo, debe leerse como una apasionada defensa y elogio del roman, cuya historia fue resumida por Balzac en unos cuantos nombres, los de sus más inmortales protagonistas: "Daphnis et Chloë, Roland, Amadis, Panurge, Don Quichotte, Manon Lescaut, Clarisse, Lovelace, Robinson Crusoe, Gil Blas, Ossian, Julie d'Étanges, mon oncle Tobie, Werther, René, Corinne, Adolphe, Paul et Virginie, Jeanie Deans, Claverhouse, Ivanhoë, Manfred, Mignon" (10). Novelas pastoriles y novelas de caballerías, novelas picarescas y novelas de aprendizaje, novelas sentimentales y novelas históricas, prácticamente todas las variedades históricas de la novela se dieron cita en este breve y selectivo repaso balzaciano de la evolución del género. Pero lo realmente importante es que la intención del escritor al recordar todo esto era reivindicar un género injustamente tratado, "un género de composición injustamente llamado secundario" (Balzac 10).

Esta reivindicación de la novela como género se hacía extensiva a todas las variedades del mismo, las realistas-picarescas, pero también, como ha podido verse, las más imaginativas y/o idealizadoras. Desde el punto de vista de Balzac, cualquiera de estas novelas, incluso la más romanesque, era infinitamente más valiosa que mucho de lo que se tenía entonces por género serio. Los argumentos con que el escritor defendió esta superioridad de la novela fueron básicamente cuatro. El primero se refería a la "dificultad" de la tarea novelesca, entendida aquí como la de crear personajes. Para Balzac, la existencia de 
Don Quijote o Manon Lescaut suponía que los escritores le hacían la competencia (faire concurrence) al Registro Civil, o dicho de otro modo, que poblaban el mundo con nuevos seres, tarea creadora esta que al autor le parecía incomparablemente más "difícil” que muchas de las pretenciosamente llevadas a cabo por historiadores, juristas, teóricos y hasta metafísicos del momento:

¿No es verdaderamente más difícil hacer la competencia al Registro Civil con Dafnis y Chloë, Lescaut [...], que ordenar los hechos, los mismos poco más o menos en todas las naciones, investigar el espíritu de leyes caídas en desuso, redactar teorías que extravían a los pueblos, o, como algunos metafísicos, explicar lo que es? (10)

El segundo argumento era el de la inmortalidad alcanzada por esos personajes de novela, cuya existencia -explicó el autor- llegaba a ser por eso más larga y auténtica que la de las personas reales, "más dilatada, más auténtica que la de las generaciones en medio de las cuales se les hace nacer" (10). El tercer argumento con que Balzac trató de ganar para la novela el lugar que sin duda merecía fue el de su peculiar fidelidad a lo real-histórico. Tal como lo veía Balzac, todos esos personajes, por irreales o ficticios que fuesen, habían sido concebidos en las entrañas (les entrailles) de "su siglo", por lo que, más allá de toda apariencia, contenían siempre una "gran imagen del presente" (10). Por último, la novela estaba muy lejos de ser un género meramente evasivo o de distracción, siendo por el contrario muy frecuente que bajo su "envoltura" sentimental se ocultase "toda una filosofía": "Todo el corazón humano se agita bajo su envoltura, y en ella se esconde a menudo toda una filosofía" (10).

Todo esto explica que Balzac hablase de la novela en su conjunto como género decididamente poético. Desde su punto de vista, antes incluso de que Walter Scott compusiera su valiosa e innovadora obra, la novela había sido parte integrante y fundamental de la "literatura" y hecho contribuciones decisivas a la "corona poética" de las naciones (10). El escritor concluyó, por eso, afirmando "la importancia y la poesía de esta historia del corazón humano" (10). La novela debía pues gozar, incluso en sus modalidades más fantásticas y menos verosímiles, de la consideración de Poesía que tanto tiempo se le había hurtado injustamente. No obstante, $\mathrm{y}$ tras haber reivindicado el valor poético de la tradición novelesca, Balzac resaltó la especial relevancia que a este respecto, el de la esencia poética del género, debía otorgarse a la reciente novela de Walter Scott, al que no casualmente se refirió en términos de "trouveur (trouvère) moderne" (10). 
Lo que hacía de Walter Scott un "bardo" no era, por supuesto, el verso, sino la mímesis. Pero lo que lo hacía "moderno" era su esfuerzo por conseguir para la mímesis novelesca el grado de verosimilitud en el que Aristóteles había hecho precisamente residir la diferencia entre Historia y Poesía. De ahí que Balzac, haciendo aquí una lectura personal de la letra de la Poética ${ }^{16}$ concediese a Scott el honor de haber elevado la novela "al valor filosófico de la historia". Merece la pena reproducir el pasaje en su totalidad porque en él se contiene no solo la comprensión balzaciana del arte de Walter Scott, sino algo muy próximo ya a lo que habría sido su propio proyecto narrativo:

Walter Scott elevaba, pues, al valor filosófico de la historia la novela, esa literatura que de siglo en siglo incrusta de diamantes inmortales la corona poética de los países en los que se cultivan las letras. Ponía en ella el espíritu de los tiempos antiguos, reunía allí a la vez el drama, el diálogo, el retrato, el paisaje, la descripción; hacía entrar en ella lo maravilloso y lo verdadero, elementos ambos de la epopeya, y hacía que la poesía se codeara con la familiaridad de los más humildes lenguajes. (10)

Que este, y no el de Buffon, fuese el verdadero modelo de Balzac explicaría la nada sorprendente presencia de elementos fantásticos o maravillosos en algunos de sus relatos. Puesto que Balzac los concibió siempre como roman, no como Ciencia, ni como Historia, nada tendría de particular que de vez en cuando, y siempre que sirviese a la finalidad "filosófica" de su obra, el autor se permitiese combinar lo "vrai" con lo "merveilleux", tal como él mismo elogió que hiciese Walter Scott. Este mismo modelo explicaría también, por supuesto, la abundante presencia en su obra de lo verdadero, incluyendo aquí esa "familiaridad de los más humildes lenguajes", elementos todos con los que el escritor habría tratado de continuar la tarea iniciada por Scott en cuanto a la conquista de la verosimilitud novelesca. Finalmente, el pasaje transcrito permite inferir que Balzac encontró en Scott la plasmación misma de la idea romántica de la novela como género en el que se reunían, confundidos, todos los demás: drama, diálogo, retrato, paisaje y descripción, a los que se podría añadir -como el propio Balzac hizo en otros textos- el de la comedia (ver Ambrière-Fargeaud 1976, 1123).

16. "Y por eso la poesía es más filosófica y noble que la historia, pues la poesía dice más bien las cosas generales y la historia las particulares" (Poética 1451b). 
Pese a todo, es completamente cierto que, como destacó Gaillard, Balzac le señaló un "défaut" a la novela de Walter Scott. Se trataba, recordemos, de la "falta" de coordinación entre sus diferentes novelas, que a Scott no se le había ocurrido relacionar para que formaran una especie de historia completa. Pero esto, comparado con todo lo anterior, no parece argumento suficiente para hacer del novelista inglés el "contra-modelo" de su narrativa. Sobre todo si se tiene en cuenta que, al señalarle esa falta, Balzac no pretendía tanto enmendarle la plana a su maestro, cuanto más bien destacar aquello en que, a su juicio, consistía su propia y modesta aportación a la historia de la novela. Puesto que, tal como él lo veía, Scott se le había adelantado ya en todo, lo único que por su parte había podido añadir a lo por él realizado había sido esa idea de ligar las diferentes novelas "una con otra con el fin de coordinar una historia completa" (11). Haciendo gala así de esa modestia con la que, al comienzo mismo del prólogo, dijo querer escribirlo, el genial novelista francés se presentó a sí mismo como un simple continuador del gran escritor inglés, cuya "fecundidad sorprendente" estaba asimismo dispuesto a emular en la medida en que se lo permitieran sus propias capacidades (11). Solo un poco más abajo, y como de pasada, se refirió Balzac a otra de las novedades representadas por su propia obra: la de haber elegido como objeto de la mímesis poética, no los tiempos antiguos que tan gratos fueron al bardo inglés, sino la realidad contemporánea, "la Francia del siglo diecinueve" (11). Pero, a diferencia de la otra, ni siquiera la destacó sobre el fondo de la diferencia con las novelas de Walter Scott.

\section{CONCLUSIÓN}

Aunque queda mucho por decir acerca de las restantes diez páginas del prólogo, es el momento de recapitular exponiendo las conclusiones de este trabajo. Mediante el análisis de una serie de textos críticos o teóricos sobre Balzac se han identificado aquí los componentes centrales de un tópico crítico-literario: el de un Balzac fascinado por la ciencia y convencido de la posibilidad de extender el saber del reino animal al reino de lo humano-social. Sin embargo, una lectura atenta del Avant-Propos ha permitido concluir que, aunque el autor sintió verdadera admiración por las innovaciones científicas de su tiempo (incluyendo aquí las del siglo XVIII), esto no derivó en su caso en la habitual confusión cientificista entre mundo natural y mundo social, ni entre sus respectivas ciencias. En lugar de eso, y a partir de un detenido desglose de las diferencias entre las especies animales y las supuestas "especies sociales", Balzac se habría 
anticipado en cierto modo a la tesis hermenéutica de la diferencia entre los objetos de conocimiento de cada grupo de ciencias y, por consiguiente, también a la tesis hermenéutica de la necesidad de estudiarlos por separado. Esto le habría llevado a descartar incluso su primera y muy modesta hipótesis acerca del "parecido" entre sociedad y naturaleza, abandonando por tanto su originario e ilusorio plan de escribir una obra como la realizada por Buffon. A tenor de lo afirmado en el prólogo de La Comedia bumana, Balzac acabó sustituyendo este plan originario por un nuevo y más complejo proyecto narrativo que, adaptado ya a la complejidad de la vida social, optó por describir en términos estrictamente humanistas, en lugar de pseudocientíficos. De ahí, precisamente, la importante comparecencia en el Avant-Propos de la Historia, cuya presencia y tratamiento en el texto avalaría la tesis, aquí defendida, acerca de la naturaleza, más hermenéutica que positivista, de la epistemología balzaciana.

Habría sido pues en la historia y no en la ciencia donde Balzac encontró finalmente el discurso epistémico con el que la novela podía compararse y medirse, objetivo para el que no solo retomó la clásica diferencia aristotélica entre lo verdadero y lo verosímil, sino que además elaboró una nueva y pre-unamuniana distinción entre la Historia de las naciones y la historia de las vidas privadas. Por último, habría sido precisamente su conciencia sobre la especificidad del discurso novelesco, no del todo identificable al histórico, lo que explicaría que, a diferencia de lo sostenido por Françoise Gaillard, el único modelo reconocido de verdad en el Avant-Propos sea la novela de Walter Scott. Balzac vio en ella el paradigma de una novela moderna, verosímil y alejada de los excesos imaginativos del roman de los siglos precedentes, pero sin por eso dejar de formar parte de la misma tradición a la que en su día pertenecieron obras como el Amadís de Gaula o el Quijote -y cuya defensa y reivindicación habría sido de hecho uno de los grandes objetivos de este texto teórico-literario-.

\section{OBRAS CITADAS}

Alborg, Juan Luis. Historia de la literatura española: realismo y naturalismo. La novela. Parte primera. Madrid: Gredos, 1996.

Ambrière-Fargeaud, Madeleine. "Introduction" y "Notes" à l'Avant-propos. La Comédie humaine. 1. Études de moeurs: Scènes de la vie privée. Ed. PierreGeorges Castex. Paris: Gallimard, 1976. 3-6 y 1110-42.

Ambrière-Fargeaud, Madeleine. "Balzac, homme de science(s): Savoir scientifique, discours scientifique et système balzacien dans La recherche de 
l'absolu". Colloque de Cerisy. Balzac: l'invention du roman. Paris: Editions Pierre Belfond, 1982. 43-55.

Aristóteles. Poética. Ed. Aníbal González Pérez. Madrid: Editora Nacional, 1982. Astruc, Rémi. Le Renouveau du grotesque dans le roman du XXe siècle: Essai d'anthropologie littéraire. Paris: Garnier, 2010.

Balzac, Honoré de. "Avant-propos". 1842. La Comédie humaine. 1. Études de moeurs: Scènes de la vie privée. Ed. Pierre-Georges Castex. Paris: Gallimard, 1976. 7-20.

Barthes, Roland. El grado cero de la escritura. 1953. Trad. Nicolás Rosa. Buenos Aires: Siglo XXI, 1973.

Barthes, Roland. S/Z. 1970. Trad. Nicolás Rosa. México: Siglo XXI, 1987.

Bayard, Pierre. Balzac et le troc de l'imaginaire: Lecture de La Peau de Chagrin. Paris: Lettres Modernes Minard, 1978.

Bray, Patrick M. "Balzac and the Chagrin of Theory". Esprit Createur 54.3 (2014): 66-77.

Brix, Michel. "Balzac et la symbolique de la peau de chagrin". Anales de Filología francesa 14 (2006): 53-68.

Brooks, Peter. L'Imagination mélodramatique: Balzac, Henry fames, le mélodrame et le mode de l'excès. Paris: Garnier, 2010.

Castelo Branco, Dilma. "Le mythe et les figures dans «La Peau de Chagrin» de Balzac". Caligrama: Revista de Estudos Românicos 4 (2011): 33-40.

Del Lungo, Andrea. "De Zadig à Vautrin: sur le paradigme indiciaire chez Balzac". Revue italienne d'études françaises 3 (2013). 4 de noviembre de 2017. <http://journals.openedition.org/rief/250>.

Del Lungo, Andrea y Boris Lyon-Caen, dirs. Le Roman du signe: Fiction et herméneutique au XIXe siècle. Saint-Denis: PUV, 2007.

Dickson, Polly. "Figures of Feeling in Honoré de Balzac's La Peau de chagrin". Nineteenth Century French Studies 45.3-4 (2017): 149-62.

Engels, Friedrich. "Carta a Miss Harkness". 1888. Marx-Engels. Textos sobre la producción artística. Ed. Valeriano Bozal. Madrid: Alberto Corazón Editor, 1976. 165-68.

Fizaine, Jean-Claude. "Ironie et fiction dans l'oeuvre de Balzac". Colloque de Cerisy. Balzac: l'invention du roman. Paris: Editions Pierre Belfond, 1982. $159-80$.

Gaillard, Françoise. "La science: modèle ou vérité. Réflexions sur l'avantpropos à La comédie humaine". Colloque de Cerisy. Balzac: l'invention du roman. Paris: Editions Pierre Belfond, 1982. 57-83. 
Huertas García-Alejo, Rafael. "La «novela experimental» y la ciencia positivista". Llull 7 (1984): 29-52.

Ledo, Jorge. "Apuntes para una teoría de lo fantástico en Honoré de Balzac". Thélème: Revista Complutense de Estudios Franceses 22 (2007): 135-66.

Lukács, Georg. "Balzac: Los campesinos". 1934. Ensayos sobre el realismo. Trad. Juan José Sebrelli. Buenos Aires: Ediciones Siglo Veinte, 1965. 31-64.

Lyon-Caen, Boris. "Balzac, une épistémologie en devenir". Poétique 135 (2003): 289-305.

Lyon-Caen, Boris. "Raconter, expliquer, comprendre: Balzac et le problème de la causalité". Poétique 172 (2012): 423-39.

Pavel, Thomas. Representar la existencia: el pensamiento de la novela. 2003. Barcelona: Crítica, 2005.

Rees, G. "The Influence of Science on the Structure of the Novel in the 19th Century". Literature and Science. PIFMLL, 6th Congress. Oxford: Blackwell, 1955. 255-61.

Rees, G. "Il método scientifico nei romanzi di Balzac, Flaubert e Zola". Letteratura e scienza. Ed. A. Battistini. Bologna: Zanichelli Editore, 1977. 196204.

Rosen, Elisheva. "Le grotesque et l'esthétique du roman balzacien". Colloque de Cerisy. Balzac: l'invention du roman. Paris: Editions Pierre Belfond, 1982. 139-57.

Thiher, Allen. Fiction Rivals Science: The French Novel from Balzac to Proust. Missouri: Missouri UP, 2001.

Villanueva, Darío. Teorías del realismo literario. $2^{\mathrm{a}}$ ed. Madrid: Biblioteca Nueva, 2004.

Warning, Rainer. Die Phantasie der Realisten. Munich: Wilhelm Fink, 1999.

Zima, Pierre. L'Ambivalence romanesque: Proust, Kafka, Musil. Frankfurt am Main: Peter Lang, 1988. 